\title{
DO ESPIRITO E CORAÇÃO EM MEDICINA
}

\author{
CONFERENCIA FEITA NO CENTRO ACADEMICO "OSWALDO CRUZ" \\ PELO
}

DR. RAUL BRIQUET

Embora conscio de que outros se desempenhariam incomparavelmente melhor do que nós do honroso encargo de realizar uma conferencia com que se commemore a fundação desta Faculdade, accedemos ao amavel convite do Centro "Oswalido Cruz" para tão só affirmar solidariedade com a mocidade academica.

A data que se celebra é, sem duvida, gratissima, e aquella em que repousam as melhores esperanças da classe medica paulista. Confrontando-a, hoje, com o que era um decennio atrás, não poderemos negar que apriceiavel beneficio ella já colheu de nossa Faculdade. Consolidaram-se reputações, e outras se formam no estimulo do magisterio onde, incandescido pelo trato com os alumnos, acrisola-se o amor ao estudo.

Commemorar a creação da Faculdade de Medicina de s. Paulo importa recordar sempre o nome de seu benemerito organizador Arnaldo de Carvalho, que conseguio, na inflexivel directriz traçada, congregar os elementos a quem confiou a efficiencia e o futuro da medicina paulista. Que jamais o esmorecimento quebrante a fé no engrandecimento desta Eistcola, e, assim, ver-se-á consagrada a magnificencia de reus ideaes.

Durante o tirocinio academico mister é que se desenvolva o raciocinio e a pratica do bem - unica base solida para futuros aperfeiconmentos.

Não obstante conhecerdes os preceitos de methodologia e cultuardes com esmero os sentimentos affectivos, quizeramos sobre o assumpto fazer ligeiras considerações, porquanto, affirma Renan, póde-se nos interstidios do trabalho e do pensamento collocar uma immensidade de cousas.

As idéas crescem em razão directa do exercicio das funcções corre- 
braes, do tempo que se consagra á meditação, e da variedade de objectos que se desenvolvem no decurso da existencia. Daí o con welho de cêdo se disciplinarem o raciocinio e os methodos a ello conducentes.

Em medicina, é verdade, o rigor logico não póde ser applicado em toda a plenitude, entretanto, por isso mesmo, cumpre não esquece-lo, sempre que possivel, afim de se attenuarem os vicios inherentes á nossa arte, de feição que se alcance desentranhar do acervo anarchico de conjecturas, mais ou menos arbitrarias, o criterio seguro da investigação clinica.

Como é sabido, a methodclogia comprehende a "inducção" e a "deducção" completando se ambas na pesquisa da verdacic.

Elabora-se a inducção da "observação", "experimentação". "comparação", que offerecem o material para a "generalização"

\section{OBSERV AÇÃO}

A observação é o substracto da medicina. "Ars medica tota in observationibus" (Bacon).

Ponderava Lamarck: "Todo conhecimento que não é producto real de observação ou de consequencias della emanadas, é inteiramente infundado e positivamente illusorio".

A observação é. tarefa dos sentidos; da percepção, em summa. Impende-lhe ser "exacta" methodica" e "completa".

Para Orfila, ( $\left.{ }^{1}\right)$ o observador deve possuir os predicados seguintes: a) "curiosidade scientifica" (desejo dé interpretar os phenomenos): b) "amor á verdade", que se trifurca elm "exactidão" (vêr o que compete, nem mais nem menos), "sinceridade" (reconhe cer factos contrarios ás idéas proprias), e "imparcialidade" (não possuir juizo aprioristico); c) "attenção"; d) "paciencia" e "xerseverança"; e) "penetração de espirito", que supera a sagachdade. "Um medico sagaz vê perfeitamente que a causa apparente de úme molestia não é a verdadeira, a passo que só a descobre o medico que possue tal qualidade" (Janet).

Necessario é apartar a "observação" de sua "interpretação": a primeira colhe, por exemplo, o symptoma; esta sobre elle emitte juizo.

$\mathrm{Na}$ maioria das vezes, o observador só procura phenomenos conhecidos; o seu merecimento está em descobrir novos aspectos áb questões.

Assim se explica porque, após a publicação de novas formula symptomaticas, reconhecem-se numerosos casos da molestia capitulada nova; o que é novo, porém, é o registo, a inclusão nosographica de syndromes mais ou menos complexas, que passaram desperceibidas ás gerações anteriores.

Preciso é levar em conta os vicios, assim de percepções falsas, como de observação propriamente, que podem ser por "deficiencia", "excesso" ou "substituição".

Vezes ha que não se consigna o facto verdadeiro: é o "êrro por deficiencia": commum aos que examinam o doente com dia(1) Pou y Orfila, autor de "Logica e Pedagogia medicas", Montevidéu 1915-1916,
excellente obra, cuja leitura nos foi muito util. 
gnostico preestabelecido, de modo que desconhecem o existente e só verificam determinados symptomas.

o "êrro por excesso" é encontradiço naquelles que recommendam novos methodos de exploração ou de therapeutica; descobrem sempre o complexo favoravel ao preconicio de suas idéas.

o "êrro por substituição", por fiim, resulta da desattenção com que se procede ao exame.

\section{EXPERIMENTAUÃO}

No conceito de Cl. Bernard, a experimentação nada mais \& que a observação provocada.

o clinico que perquire symptomas para verificação diagnostica, ou recommenda uma medicação qualquer, soccorre-se do mothodo experimental porquanto não se podem prejulgar as reacções organicas promovidas pela molestia ou pelo tratamento.

Impõe-se muita prudencia no apreciar a transferencia ao organismo humano vivo dos resultados de experimentos executados fóra delle. $O$ delicado determinismo, imprescindivel para lhes conferir efficacia, torna-se muitissimo complexo no caiso de molestia.

\section{COMPARAÇÃO}

A observação e a experimentação associadas constituem a "comparação" ou "observação comparativa" que exige duas experiencias - a "prova" e a "contra-prova". Cl. Bernard conferia importancia substancial a esta, pois "a unica prova que um phenomeno desempenha papel de causa em relação a outro", affirmava o grande physiologista, é "fazer cessar o segundo, supprimindo o primeiro"

Posto que em medicina o recurso da comparação seja precario, em virtude da difficil reducção á unidade das divergencias especificas nos typos considerados, muito se deve esperar desse methodo para o progresso de nossos conhecimentos.

A comparação é de adoptar-se em todos os casos que não comportam o methodo experimental, e preenche as falhas que este e a observação possam apresentar.

Como á observação, cabe ao methodo comparativo apontar ou disnôr o material utilisavel pelos experimentos.

\section{CONDICIONALIDADE}

O objectlivo da investigação é a "causa", isto é, a actuação de factores no apparecimento de phenomenos. Referimo-nos á causa proxima, e não á remota ou primaria, cogitação van, uma vez conhecilas as leis que regem os respectivos phenomenos.

A tendencia moderna é averiguar as "condições" que provocam तeterminado jhenomeno, quer dizer, o problema da "condicionalidade" prevalece ao da causaliidade, com o qual, estrictamente falando, se confunde, porquanto a causa se póde reduzir a um conjunto de condições.

o essencial é repellir o habito de invocar-se pluralidade de causas para um mesmo effeito, tal no problema etiologico da eclampsia; ou, inversamente, admittir-se causa unica e exclusiva para effeitos diversos, como na etiologia dos tumores, em que a argucia 
de numerosos indagadores se tem quebrado de encontro a rssa preconcebida idéa.

A doutrina da condicionalidade deve subordinar-se ao criterio de positividade (exactidão e destimação pratica).

\section{HYPOTHESE}

A observação conduz á "hypothese", supposição não confirmada; quando provada, constitue a "theoria". Apesar desta simplicidad definitiva, é vulgar promover a theorias hypotheses arrevesadas e illogicas. Em separar o facto da hypothese está o criterio.

$\mathrm{Na}$ hypothese devem obesrvar-se os seguintes principios: a) primordialmente, a "simplicidade", consoante a primeira lei universal: "formar a hypothese mais simples e mais sympathica que comporta o conjunto des dados a represntar". b) secundariamente: a "anaJogia" (effeitos id nnticos lecorrem de causas identicas); a "adaptação" (funcções normaes e palhologicas implicam correspondencia nos respectivos orgams), e a "evolução" (os phenomenos physiopathologicos são evolutivos).

A hypothese deve assentar-se em langa observação, jámais dispensando a demonstração comparativa.

Sempre que se invocam varias hypotheses sobre um mesmo probleme, por vezes contraditorias, manda o bom senso que se faça integral revisão de seu estudo.

\section{DEFINIÇÃO}

Vicio que anarchisa o methodo é a "definição" defeituosa.

Devia considerar-se um deus, dísse Piatão, aquelle que soubesso bem definir e dividir.

A definição deve ser: "breve" - excluir o que compete á descripçäo e só mencionar os seus componentes insubstituiveis; "essencial" - indicar o genero proximo a que se subordina e a differença especifica que a distingue; e "equivalente" ou "reciproca" abranger todo o definido e só elle. Não deve ser: "circular" redigida com palavra que se define ou lhe seja synonyma; "obscura" - formulada com vocabulos destituidos de significação clara; e "negativa", isto é, deve preferir-se sempre a affirmação de um facto á sua negação.

Pascal aconselhava evitar a ambiguidade dos vocalsulos, substituindo-os mentalmente pelas definições que os restringem e explicam. Póde-se, outrosm, troca-los pela expressão antonyma

\section{LINGUAGEM MEDICA}

A definição requer vocabulario adequado. Nunca é ocioso esmerar sse na selecção das palavras, em sua propriedade e pureza Quantas discussões cessariam uma vez acertada a terminologia!

A nomenclatura medica é confusa e, sob certo aspecto, inaccessivel á melhor retentiva. Como guardar a serie interminavel de nomes proprios que significam, a miude, coisas rasteiras na importancia? Nesse particular, seria recommendavel pespor-se sempre o nome do autor á designação do facto ou phenomeno. Assim, dir-se-ia bacia obliqua ovalar, de Naegels, e não, simplesmente, bacia de Naegele; pulso puerperal de Blot, e não apenas pulso de Blot, etc. 
E' censuravel o vêzo de se caracterisarem os phenomenos biologicos como se os respectivos agentes possuissem consciencia psychica: é o que se chama "descripção vitalista anthropomorphica" Em identico reparo incorrem as "metaphoras teleologicas".

Expurgue-se a linguagem medica de taes excrescenciás que dejồem contra o espirito criterioso.

A.o investigador não corre senão o dever de expôr os factos como se verificam e produzem, apontando o seu determinismo, sem preoccupações de causas primarias ou finaes.

\section{DIVISÃO}

Comprehende-se a utilidade de divisões, obedecendo á regra cartesiana de "percorrer para complemento da sciencia, em movimente continuo do pensamento, todos os objectos que se prendem ao nosso fim, e abrange-los em sufficiente e methodica ennumeração.

Baseada em caracter importante e esisencial, a divisão deve ser: "total"; "opposta", isto é, as partes devem excluir-se reciprocamente; "gradual", obedecendo á gradação natural, anatomica ou physiologica; e "proporcionada", a saber, nem excessiva, nem insufficiente.

Orfila recommenda a seriação seguinte: chronologica, dimensoria, morphologica, e, segundo a oodem expositiva: etiologica, pathogenica, physio-pathologica, anatomica, pathologica, symptomatologira, diagnostica, prognostica e therapeutica.

$\mathrm{Na}$ divisão segundo as "semelhanças" e "differenças" que constitue a "ciassificação", levar-se-à em conta a hierarchia scientifica, e. respeitante á physiologia, p. ex., enunciam-se as funç̧ões de accôrdo com a enunciação philosophica.

\section{DIAGNOSTICO}

A applicação medica, por excellencia, dos methodos inductivo e deductivo depara-se no problema do "diagnostico".

Induz-se quando se procuram symptomas e signaes clinicos.

Deduz-se impondo ao caso clinico o "syllogismo", instrumento do methodo, que comprehende, como se sabe, duas premissas (maior ou menor) e a conclusão.

A premissa maior corresponde ao conceito da molestia e sua caracterização universal; a menor á observação do caso clinico, e a conclusão ao diagnostico.

Distinguem os autores, e com elles Orfila, a quem seguimos de perto neste passo, dois objectivos no diagnostico: I) conforme os factos, a saber, aquillo que se pesquisa (quid diagnosticandum); II - consoante o criterio ou como se procede (quomodo diagnosticandum).

O primeiro (I) (quid diagnosticandum) abrange dois fins: A) a molestia; B) as condições sociaes do doente.

A) O diagnostico da molestia, ou "pathologico" propriamente, considera a evolução e o estado presente do processo morbido e concerne: 1) á "molestia"; 2) ao "doente" (factores intrinsecos). Subdi-
ride-se o driagnostico da molestia em: a) "somatico" e b) "psychologico". 
Consta o diagnostico "somatico" do "anatomo-pathologico," funccional" ou physio-pathologico" e "condicional" (etiologia a pathogenia).

O "anatomo-pathologico" responde ao quesito "ubi est morbus?"; o "funccional" delles o mais philosophico, baseia-se no conceito synergico das funcções hygidas ou perturbadas; 0 "condictonal" ou "causal" estuda as condições ou causas de apparecimento da molestia e seu modo de actuação.

No diagnostico "psychologico" indaga-se o factor moral. Elle inclue, em rigor, no exame funccional.

2) Quanto aos factores intrinsecos, o diagnostico do doente averigua a edade, sexo, temperamento, etc., e é chamado "individual"; investiga, em summa, a questão do "terreno".

F) No diagnostico "social": inquirem-se os factores que definem o doente na sociedade: hereditariedade, profissão, etc.

II Conforme o "methodo" adoptado, ("quomodo diagnosticandum"), o diagnostico é: A) intuitivo"; B) "racional"; C) "intuitivo-racional"; e D) "classificador".

A) No "intuitivo" ou "synthetico", colligem-se os sigmaes e symr ptomas, que serão cotejados em quadros symptomaticos verificados em outros doentes.

B) Esmiuçam-se, successivamente, no "racional" ou "analytico" as diversas desordens funccionaes e organicas.

Como se deprehende, o diagnostico "intuitivo" vale-se, de preferencia, dos ensinamentos theoricos, e o "racional" da experiencia clinica; o mais consentaneo, todevia, é fundi-los no methodo "intuitivo-racional" (C).

o diagnostico "clasisificador", ainda denominado "nominal" ou "nosographico" inclue o juizo clinico no conjunto das molestias. Represienta a systematização.

Comprehende este methodo cinco variedades: 1) "positivo"; 2) "differencial"; 3) "por exclusão"; 4) "inductivo"; 5 ) "deductivo" este bipartindo-se em a) "ex-juvantibus", e b) "ex-nocentibus".

1) No diagnostico "positivo", estudam-se as manifestações proprias a determinada molestia; buscam-se-lhe as analogia's, de onde tamibem o nome de "diagnostico por analogia".

Os symptomas, aqui, se dividem em "pathognomonicos" ou "communs" e "constantes" ou "inconstantes".

Diz-se: " $\mathrm{X}=\mathrm{A}$ ", porque " $\mathrm{X}$ " possue caracteres identicos á descripção classlica de "A".

2) No diagnostico "differencial", por via de regra complementar do precedente, compara-se determinado cortejo symptomatico as de outras molestias similares, e avaliam-se as analogias e differenças encontradas, quer positivas, quer negativas.

Exprime-se " $X=A$ " não só porque " $X$ " poissue symptomatologia igual a de "A", como por não ser "B" ou "C".

Nesse methodo, grupam-se os symptomas em "positivos" e "negativos"; ou "presentes", "ausentes" e "excedentes".

Denominam-se "indices differenciaes" os caracteres que permittem discernir uma molestia de outras (Bieganski).

Para facilidade de estudo, convem distribuir os symptomas em "quadros de comparação" ou "parallelos", onde as linhas verticaes se destinem aos indices differenciaes, $\theta$ as horizontaes ás molestias que se irão discriminar. Taes quadros se dizem "binarios" quando comprehendem duas molestias, "ternarios", se três, etc., e têm a 
vantagem de apresenta rem, em synopse, as divergencias clinicas fundamentaes. Com elles póde cotejar-se este ou aquelle symptoma em varios processos morbidos.

Formulam-se as hypotheses que o exame clinico autorisa, analysam-se os symptomas que são apreciados nos casos em que poderiam ser presentes, constituindo este acto a contra-prova. Evidentemente, o medico remontará á anamnese inclusive.

Varlias hypotheses podem verificar-se.

Primeira: - Quando os symptomas "ausentes" e "excedentes" predominam, em qualidade e quantidade, sobre os "presentes" exclue se "A" (Primeira hypothese para considerar-se).

Segunda: - Quando os symptomas "presentes" têm primazia sobre os "ausentes" e "excedentes": conclue-se pela existencia de "A".

Terceira: - Quando as três variedades de symptomas se equivalem, o diagnostico fica suspenso por duvidoso.

Assim, seguidamente, para as hypotheses "B", "C": "D", etc.

Quarta: - Quando os symptomas "excedentes" soprepujam, em importancia, os "ausentes" e presentes", a hypothese de syndromes novas, isto é, de entidade clinica desconhecida, deve ser encarada.

- 3) No diagnostico "por exclusão", affırma-se que $\mathrm{X}=\mathrm{A}$ porque “A" não póde ser "B" nem "C". O êrro está em não se abrangerem todas as hypothesses possiveis, pois perfeitamente poderia acontecer que " $X$ " não sendo " $A$ " “B" ou " $C$ ", fosse “ $D$ ", hypothese não considerada. $\mathrm{E}$ ' indispensavel, portanto, preliminarmente estabelecerem-se as hypotheses viaveis, affirmando que " $X$ " só póde ser "A", "B" ou "C" Neste processo, assevera-se a analogia de uma molestia pelas suals differenças symptomaticas.

- 4) Quando se applica o methodo "inductivo" levanta-se, depois de registados os isymptomas, uma hypothese provisoria que será opportunamente confirmada ou negada pela marcha da molestia. Não é recommendavel porquanto escapam-lhe complicações importantes, e não exclue a existencia contemporanea de varios processos morbidos.

- 5) o diagnostico deductivo é limitado em suas applicações por depender do resultado therapeutico obtido com medicações havidas por especificas.

Se o tratamento for efficaz, (hypothese positiva), o diagnostico diz-se "ex-juvantibus" (de "juvare", melhorar); se peora o estado do doente, (hypothese negativa), denomina-se "ex-nocentibus" (de "nocere": prejudicar).

Percebe-se quanto é vago tal criterio. Seria preciso, preliminarmente, comprovar a existencia de medicações especificas, no sentido de officacia exclu'siva a determinadas molestias, curando-as só e não outras. Demais, incidie-se no sophisma do "posi hoc, ergo propter hoc", attribuindo-se á medicação a melhoria ou o aggravamento que poderia resultar, respectivamente, de factores estranhos.

o raciocinio no diagnostico "ex-juvantibus" seria, por exemplo:

"O quinino melhora os casos de impaludismo".

"O caso presente melhorou depois do uso de quinino"

"O caso presente é de impaludismo"

No diagnostico "ex-nocentibus" mais sensivel é a fallacia.

0 facto de não melhorar o doente com o medicamento reputado aspecifico não póde invalidar o diagnostico. Por outro lado, "peorar" 
e "não melhorar" são coisas distinctas, sendo impossivel affirmár que a melhora não se observou por causa da medicação.

0 raciocinio neste caso seria:

"O tratamento pele quinino molhora os casos de impalucismo"

"O caso presente não melhorou, ou peorou, depois do tratamento pelo quinino".

"O caso presente não é de impaludismo"

\section{CONCEITO DE MOLES'TIA}

Muita vigilancia se torna necessaria para forrar-se o medico ao. sophismas do raciocinio syllogistico. Deve-se, por isso, antes de tudo, firmar o verdadeiro conceito de molestia.

Em contraste com a harmonia individual, que traduz o estado hygido, a molestia caracterliza-se pela ausencia de unidade no conseniso organico.

São identicas as leis que presidem ao estado de saude ou ao de molestia, resuitandc este, de accôrdo com a primeira lei geral, abaixo mencionada, das oscillações do estado normal além de seus limites de modificabildade.

Três leis universaes esta'belecem as relações da prathologia com o conjuncto da ordem natural.

Primeira lei: "as modificações quaesquer da ordem universal limitam-se sempre á intensidade dos phenomenos cujo arranjo permanece inalteravel"

Segunda lei. "Todo o estado, estatico ou dynamico, tende a persistir espontaneamente sem nenhuma alteração, resistindo ás perturbações exteriores"

'Terceira lei: "existe por toda a parte uma equivalencia necessaria entre a reaç̧ão e a aç̧ão, se a intensidade de ambas fôr medida conformemente á natureza de cada conflicto".

$\mathrm{Na}$ investigação das condições que provocaram o estado de molestia deve cuidar-se do facto moral - "egoistico" por cxcesso, ou "altruistico" por insufficiencia - para entender-se a genese do estado morbido.

Em regra, é o predominio do primeiro que rompe o equilibrio cerebral indispensavel á integridade das funcções organicas. Tal preponderancia representa os factores predisponentes, ou o terreno, no qual vão influir as causas determinantes.

Se bem 0 altruismo raramente possa acarretar consequencias morbidas, explicam-se ellas nos individuos que, dotados de intensa sympathia universal, se despreoccupam das imposições indeclinaveis á manutenção corporal.

Como o processo physio-prathologico não se evidencia, de modo manifesto, em seus prodromos, deve o clinico referir-lhe a filliação, emprestando subido valor á anamnese. Os resultados desse interrogatorio podem ser contraprovados na observação do processo, gradual e lento, com que na convalescença o organismo retorna, por marcha inversa, ao equilibrio primitivo.

A segunda lei, (relações do organismo com o meio), esclarece a vulnerabilidade do prognostico. Resalta na tendencia espontanea de normalizar-se o organismo doente, e, ante essa lei universal, o medíco saberá reprimir seus impulsos intervencionistas, só autorisaveis quando resolvam necessidade inaldiavel. 
Consoante a terceira lei, (reacções e acções verificaveis entre os diversos elementos do organismo, quer no estado de saude, quer no estado de molestia), a equivilencia estabelece-se inicialmente entre o organismo $\epsilon$ o meio, depois entre o cerebro e as visceras e, por fim, entre os diversos apparelhos da economia.

Segundo os dictames deste principio, a therapeutica tem por escopo primacial indicar normas geraes de "regime", (regras moraes e hygienicas), dentro das quaes o organismo evolverá para o restabelecimento.

Convem ser meticuloso na iniensidade dos recursos therapeuticos convocados para reequilibrar os desvios organicos. Evitar-se-ão soluções perturbadoras que não correspondem ao conceito de molestia, nem á resistencia vital de cada tecido ou orgam diversamente compromettido pelo processo morbido.

Jamais se olvidará a advertencia de "Comte": "o êrro logico essencial da medicina consiste em applicar processos geraes a casos especiaes".

Em regra, o espirito avassaia o coração produzindo trabalhos qu? não consultam o estreitamento dos laços sociaes, objectivo de toda obra realmente util.

Tudo quanto nos torna mais sympathicos, melhores, ensina "Audiffrent" deve tornar-nos mais intelligentes e activos e, por consequencia, mais synergicos.

Como condição fundamental de exito sobrelevam os sentimentos ąltruisticos, isto é, os impulsos que partem do coração - unico movel de nossas acções.

Que valem doutrinas assentes em solida erudição se lhes fallece a virtude de tornar o medico solidario com a dôr alheia?

Só na pratica da bondade se supprem as desintegrações de energia que reclama a pratica medica. A prova está na observação diaria de que, regra geral, melhor curam os profissionaes que, perscrutando os conflictos da alma humana, sabem nella reflorir esperanças e serenar tormentas.

$\mathrm{Na}$ contemplação da morte accendra-se a grandiosidade de nossa missão; importa desenvolver tal receptividade que comprehenda, ñ visão evocadora dos que debalde imploraram a arte, como se ella encolhe modesta, e reduzida a coadjuvar a natureza no momento propicio.

Não se encarem só o caso clinico e os phenomenos que lhe são decorrentes. Ao abeirar-se do ancião alquebrado, percorram-se, em sua face arregoada, as vicissitudes de quem venceu meia centuria de lutas, e prede se lhe prolongue o occaso da vida onde se esgarçam seus derradeiros sonhos.

Attentae no sentimento determinante da indicação operatoria que se não sotopoz á vaidade pessoal. Descobri na inquietude do cirurgião o accidente imprevisto que põe em risco a vida do operado. Se a morte zomba da diligencia no salvar, fluctua a interrogação angustiosa sobre se a conducta foi irreprehensivel, se não houve açodamiento ou dilação, e se, de facto, fôra necessario o recurso sangrento.

Evitae as apreciações que maculam o credito do clinico mal afortunado. Distingui a impericia e desidia da fallencia therapeutica que não depende de exactidão no diagnostico e tratamento. Recor- 
dae-vos do coefficiente :rreductivel de lethalidade, que se subtráe ás previsões. Sejamos generosos para com o êrro alhio: a arte não exige nem comporta a precisão da sciencia.

Não afagueis da medicina senão a opportunidade de derramar beneficios. Outr'ora, era ella praticada sómente por quem decidida vocação ou bastos recursos economicos permitissem a realização do nobilissimo sacerdocio. Hoje, muitos fizeram della mercatura innominavel: o doente é um algarismo; a caridade, um trafico.

Só se legitıma no mediico uma indifferença - a dio modo polo qual serão compensados seus cuidados e devotamentos. Quauto se acertam comnosco as palavras de "Marco Aurelio": "só aos medi:cos, como aos reis, é dada a gloria de praticar o bem, sem cuider em sua correspondencia"

Não se arrefeçam os impulsos de bemfazer trás as brechas que, porventura, o desagradecimento tenha aberto no coração. Interpretem-se os aggravos do cliente desditoso como estimulo para aperfe:çoar a arte. Extinga-se em nosso regaço o éco das injurias, pois comprehender é perdoar.

Prevalecei-vos desta sazão fugiaz para praticardes a camaradagem em sua ampla accepção, acatando o direito alheio e applaudindo o merito do companheiro. o estudo collectivo gera um parentesco moral que frondeja na convergencia das aspirações.

Do coração vêm os grandes pensamentos, disse "Vauvenargues" Por isso é que o espirito só assimila os grandes surtos do entendi.mento quando os envolva sympathia profunda pela obra do prassado e pelo trabalho intelligente dos coetaneos. Possam as nossas acções attestar sempre o zelo incessante em prol da humanidade synthetisada numa cadeia indivizivel de amor.

Compraz-se o espirito na contemplação do caminho percorrido. Cumpre tecer em suavidade o manto de evocações sob o qual. ao fim da jornada teremos de abrigar-nos. Que nenhuma imprecação turve a paz merecida e lambrança alguma de descaridade ou inldifferença ensombre o encantamento do dever cumprido. 